\title{
Effect of oral beta-blocker on short and long- term mortality in patients with acute respiratory failure: results from the BASEL II-ICU study
}

Markus Noveanu', Tobias Breidthardt ${ }^{1}$, Tobias Reichlin², Etienne Gayatt, Mihael Potocki ${ }^{2}$, Hans Pargger ${ }^{4}$, Antje Heise ${ }^{5}$, Julia Meissner ${ }^{1}$, Raphael Twerenbold ${ }^{1}$, Natalia Muravitskaya ${ }^{1}$, Alexandre Mebazaa ${ }^{3}$, Christian Mueller ${ }^{1 *}$

\begin{abstract}
Introduction: Acute respiratory failure (ARF) is responsible for about one-third of intensive care unit (ICU) admissions and is associated with adverse outcomes. Predictors of short- and long-term outcomes in unselected ICU-patients with ARF are ill-defined. The purpose of this analysis was to determine predictors of in-hospital and one-year mortality and assess the effects of oral beta-blockers in unselected ICU patients with ARF included in the BASEL-II-ICU study.
\end{abstract}

Methods: The BASEL II-ICU study was a prospective, multicenter, randomized, single-blinded, controlled trial of 314 (mean age 70 (62 to 79) years) ICU patients with ARF evaluating impact of a B-type natriuretic peptide- (BNP) guided management strategy on short-term outcomes.

Results: In-hospital mortality was 16\% (51 patients) and one-year mortality 41\% (128 patients). Multivariate analysis assessed that oral beta-blockers at admission were associated with a lower risk of both in-hospital (HR 0.33 (0.14 to $0.74) P=0.007)$ and one-year mortality (HR $0.29(0.16$ to 0.51$) P=0.0003)$. Kaplan-Meier analysis confirmed the lower mortality in ARF patients when admitted with oral beta-blocker and further shows that the beneficial effect of oral beta-blockers at admission holds true in the two subgroups of patients with ARF related to cardiac or noncardiac causes. Kaplan-Meier analysis also shows that administration of oral beta-blockers before hospital discharge gives striking additional beneficial effects on one-year mortality.

Conclusions: Established beta-blocker therapy appears to be associated with a reduced mortality in ICU patients with acute respiratory failure. Cessation of established therapy appears to be hazardous. Initiation of therapy prior to discharge appears to confer benefit. This finding was seen regardless of the cardiac or non-cardiac etiology of respiratory failure.

Trial registration: clinicalTrials.gov Identifier: NCT00130559

\section{Introduction}

Acute respiratory failure (ARF) is responsible for about $30 \%$ of intensive care unit (ICU) admissions and is a major complication in patients already treated in the ICU [1-3]. This serious condition was shown to be associated with high morbidity and mortality rates [1-4]. Acute decompensated heart failure (ADHF), community acquired pneumonia (CAP), acute exacerbation of

\footnotetext{
* Correspondence: chmueller@uhbs.ch

'Department of Internal Medicine, University Hospital Basel, Petersgraben 4, 4053 Basel, Switzerland

Full list of author information is available at the end of the article
}

chronic obstructive pulmonary disease (AECOPD), pulmonary embolism (PE) and asthma are responsible for the vast majority of ICU hospitalization due to respiratory failure [5]. In-hospital mortality in ICU patients with respiratory failure is more than twice the mortality related to other ICU admissions [3].

Although mortality rates have been described in specific patient groups admitted for heart failure [6-8], severe AECOPD [9-11] or severe CAP [12-14], data concerning mortality rates and predictors of outcome in ICU patients with acute respiratory failure regardless of causal etiology are scarce. This is important for the reason 
that respiratory failure in one-third of ICU patients is multi-causal [15].

Accordingly, the aim of the present study was to assess in-hospital and one-year mortality in a cohort of consecutive ICU patients with acute respiratory failure indifferent of underlying etiology. We specifically determined the independent predictors of in-hospital and one-year mortality and assessed the impact of betablocker at admission and/or at discharge on outcome.

\section{Materials and methods}

\section{Setting and study population}

This report is a sub-study of the B-type natriuretic peptide (BNP) for Acute Shortness of Breath Evaluation (BASEL) II-ICU trial [15]. The goal of the BASEL II-ICU trial was to evaluate impact of a BNP-guided management strategy on outcome (hospital length of stay and costs) in ICU patients with acute respiratory failure. The BASEL II-ICU trial was a prospective, randomized, controlled, singleblinded multicenter study. Patients were enrolled in seven ICUs (one medical and one surgical ICU of a primary care facility and five interdisciplinary ICUs of tertiary referral hospitals) in Switzerland from December 2004 to March 2007. The study was carried out according to the principles of the Declaration of Helsinki and approved by the ethical committee responsible for each hospital. Written informed consent was obtained from patients or their surrogate. Details regarding study design has been published elsewhere [15]. In brief, patients presenting with acute respiratory failure severe enough to require ICU monitoring and treatment were randomized into one of two different diagnostic strategy groups. One of these groups included admission BNP value in addition to standard diagnostic workup (BNP group), while the other group did not have BNP values (control group).

Important exclusion criteria of the BASEL II-ICU trial were an obvious trauma, a BNP measurement within the preceding six hours, severe renal disease (serum creatinine $>250 \mu \mathrm{mol} / \mathrm{L}$ ), more than 12 hours since the eligibility criteria in the ICU were met, sepsis, cardiopulmonary resuscitation within 12 hours or shock.

The adjudicated diagnosis, used in the present study, was performed by two ICU specialists on the basis of all available medical records, the response to therapy and autopsy results in those patients who died in the hospital. Adjudicated diagnosis was performed by choosing one or more diagnoses from a pre-specified list that included the following items: HF, pneumonia, AECOPD/Asthma, pulmonary embolism (PE), atelectasis, mechanical airway obstruction, pneumothorax, other or unknown. The study protocol of the BASEL II-ICU study had no influence on mechanical ventilation or non-invasive ventilation (NIV) therapy. The decision about medical treatment including NIV or mechanical intubation was made solely by the ICU staff in charge following the current guidelines of the respective hospital.

The study included 314 ICU patients with acute respiratory failure. A one-year follow-up, assessed by telephone interview of the patients, their family or the referring physician, was completed in 311 (99.3\%) of patients representing our study population.

\section{Statistical analysis}

The statistical analyses were performed with the use of the SPSS/PC software package (version 15.0, SPSS Inc., Chicago, IL, USA). Comparisons were made using the t-test, Mann-Whitney U test, Fisher's exact test and chisquare test as appropriate. Mortality risk was estimated using the Kaplan-Meier method. All prognostic relevant characteristics were identified using univariate Coxregression analysis. The model for in-hospital mortality included the following characteristics: age, systolic and diastolic blood pressure, heart rate, breathing frequency, Glasgow coma scale, body temperature, body mass index (BMI), history of malignancy, history of congestive heart failure (CHF), history of coronary artery disease (CAD), left ventricular ejection fraction, atrial fibrillation, admission $\mathrm{pH}, \mathrm{HCO} 3$, base excess, $\mathrm{PO} 2 / \mathrm{FiO} 2$ ratio, sodium, potassium, C-reactive protein, hemoglobin, white blood count (WBC), partial thromboplastin time (PTT), creatinine, blood urea nitrogen (BUN) and uric acid levels, need for mechanical intubation, need for non-invasive ventilation, need for catecholamine and admission medical treatment (diuretics, nitrates, angiotensin converting enzyme inhibitor (ACEi)/angiotensin receptor blocker (ARB), betablockers, statins, aspirin (ASS)/clopidogrel, calcium antagonists, coumarines, beta-mimetics, steroids). For the one-year mortality model, discharge medication was added to all variables included in the in-hospital mortality model. All variables of the in-hospital and one-year mortality model with a univariate $P$-value $\leq 0.05$ were each included in the two multivariate Cox-proportional hazard models.

\section{Results}

\section{Patient characteristics and mortality}

A total of 314 ICU patients (median age 70 IQR (62 to 79) years) with acute respiratory failure were analyzed in the present study. Patient characteristics are displayed in Table 1. Final discharge diagnoses are displayed in Table 2. ICU median (range) length of stay (LOS) was 3 (2 to 4 ) days and median in-hospital LOS 14 (9 to 22) days. Overall in-hospital mortality was 16\% (51 patients), 30 -day mortality was $20 \%$ (61 patients) and one-year mortality was $41 \%$ (128 patients).

\section{Risk factors of one-year and in-hospital mortality}

Univariate analysis demonstrates that age, a history of $\mathrm{CAD}$ or malignancy, BMI, diastolic blood pressure, atrial 
Table 1 Baseline characteristics of study population

\begin{tabular}{|c|c|c|c|c|c|c|c|}
\hline & $\begin{array}{l}\text { All studied } \\
\text { patients } \\
(n=314)\end{array}$ & $\begin{array}{l}\text { In-hospital } \\
\text { survivors } \\
(n=263)\end{array}$ & $\begin{array}{c}\text { In-hospital } \\
\text { non-survivors } \\
(n=51)\end{array}$ & $P$-value & $\begin{array}{l}\text { One-year } \\
\text { survivors } \\
(n=183)\end{array}$ & $\begin{array}{c}\text { One-year } \\
\text { non-survivors } \\
(n=128)\end{array}$ & $P$-value \\
\hline \multicolumn{8}{|l|}{ Demography/Scores } \\
\hline Gender (male) - $n(\%))$ & $181(58)$ & $147(56)$ & $34(68)$ & 0.15 & $100(55)$ & $78(61)$ & 0.27 \\
\hline Age (year) & $70(62$ to 78.75$)$ & $70(61$ to 79$)$ & $73(63$ to 76$)$ & 0.013 & $69(60$ to 77$)$ & $74(64$ to 80$)$ & 0.003 \\
\hline $\mathrm{BMI}^{\mathrm{a}}$ & $25.8(22.6$ to 30.8$)$ & $25.85(22.6$ to 30.8$)$ & $\begin{array}{l}25.8(22.5 \text { to } \\
28.4)\end{array}$ & 0.06 & $26.15(23.4$ to 31.1$)$ & $25.3(21.2$ to 29.1$)$ & 0.008 \\
\hline SAPS ${ }^{b} \|$ score & $32(26$ to 46$)$ & $32(24$ to 45$)$ & 36 (31 to 46$)$ & 0.12 & $32(24$ to 45$)$ & $44(30$ to 44$)$ & 0.07 \\
\hline \multicolumn{8}{|c|}{ Hemodynamic parameters } \\
\hline Heart rate (bpm) & 98(84 to 116$)$ & $97.5(83.75$ to 115$)$ & 105(85 to 123$)$ & 0.16 & $98(83$ to 116$)$ & $\begin{array}{l}100(84 \text { to } \\
115.25)\end{array}$ & 0.8 \\
\hline $\begin{array}{l}\text { Systolic blood pressure } \\
(\mathrm{mmHg})\end{array}$ & $127(111$ to 148$)$ & $128(111$ to 148$)$ & $127(111$ to 139$)$ & 0.34 & $129.5(111$ to 150$)$ & $126(112$ to 143$)$ & 0.19 \\
\hline $\begin{array}{l}\text { Diastolic blood } \\
\text { pressure }(\mathrm{mmHg})\end{array}$ & $67(56$ to 80$)$ & $67(57$ to 80$)$ & $64(53$ to 78$)$ & 0.17 & $70(59$ to 82$)$ & $62(53$ to 74.5$)$ & 0.006 \\
\hline $\begin{array}{l}\text { Mean arterial pressure } \\
(\mathrm{mmHg})\end{array}$ & $85(73$ to 100$)$ & $87(74$ to 101$)$ & $85(73$ to 96$)$ & 0.15 & $89(76.25$ to 103$)$ & $83(71.5$ to 95$)$ & 0.04 \\
\hline $\begin{array}{l}\text { Left ventricular ejection } \\
\text { fraction }(\%)^{c}\end{array}$ & $55(35$ to 60$)$ & $50(35$ to 60$)$ & $60(35$ to 65$)$ & 0.35 & $50(35$ to 60$)$ & $60(43.5$ to 63.75$)$ & 0.26 \\
\hline Atrial fibrillation- $n(\%)$ & $50(16)$ & $37(14)$ & $13(26)$ & 0.04 & $22(12)$ & $28(22)$ & 0.02 \\
\hline \multicolumn{8}{|c|}{ Respiratory/metabolic parameters } \\
\hline $\begin{array}{l}\text { Mechanical ventilation - } \\
n(\%)\end{array}$ & $42(13)$ & $34(13)$ & $8(16)$ & 0.59 & $26(14)$ & $16(13)$ & 0.66 \\
\hline $\begin{array}{l}\text { Non-invasive } \\
\text { ventilation - } n(\%)\end{array}$ & $158(50)$ & $131(59)$ & $27(53)$ & 0.68 & $87(48)$ & $70(55)$ & 0.21 \\
\hline $\begin{array}{l}\text { Breathing frequency } \\
\text { (cpm) }\end{array}$ & $24(19$ to 30$)$ & $24(19$ to 30$)$ & $25(20$ to 30$)$ & 0.75 & $24(18$ to 30$)$ & $25(20$ to 30$)$ & 0.38 \\
\hline $\mathrm{PaO} 2 / \mathrm{FiO} 2$ & 161(101 to 240$)$ & 169(101 to 239) & 144 (92 to 216$)$ & 0.20 & 169 (99 to 248$)$ & $152(100$ to 228$)$ & 0.41 \\
\hline $\mathrm{PaCO} 2(\mathrm{kPa})$ & $5.9(4.9$ to 7.8$)$ & $5.9(5$ to 7.8$)$ & $5.8(4.8$ to 8.2$)$ & 0.33 & $5.9(5$ to 7.5$)$ & $6.05(4.8$ to 8.4$)$ & 0.34 \\
\hline \multicolumn{8}{|l|}{ Laboratory parameters } \\
\hline Hemoglobin $(\mathrm{g} / \mathrm{l})$ & $118(101$ to 141$)$ & $120(102$ to 142$)$ & 108(97 to 128$)$ & 0.04 & $121(101$ to 145$)$ & 114(100 to 134$)$ & 0.013 \\
\hline Uric acid $(\mu \mathrm{mol} / \mathrm{l})$ & $381(275.5$ to 502$)$ & $370(274$ to 494.5$)$ & $412(311$ to 521$)$ & 0.31 & $362(278$ to 470.5$)$ & $397(273$ to 557$)$ & 0.10 \\
\hline $\begin{array}{l}\text { eGFR MDRD }{ }^{d}(\mathrm{~mL} / \mathrm{min} / \\
\left.1.73 \mathrm{~m}^{2}\right)\end{array}$ & $69(46$ to 99$)$ & $71.5(46$ to 102$)$ & $56(45$ to 88$)$ & 0.04 & $72(49$ to 102.75$)$ & $60.5(41.75$ to 95$)$ & 0.08 \\
\hline $\begin{array}{l}\text { Blood urea nitrogen } \\
(\mathrm{mg} / \mathrm{dl})\end{array}$ & $21(13$ to 33$)$ & $19(12$ to 31$)$ & $26(18$ to 38$)$ & 0.04 & $19(12$ to 28$)$ & $24(14$ to 39.5$)$ & 0.01 \\
\hline \multicolumn{8}{|l|}{ Comorbidities to $n(\%)$} \\
\hline History of heart failure & $85(27)$ & $71(27)$ & $14(28)$ & 0.94 & $48(26)$ & $37(29)$ & 0.60 \\
\hline $\begin{array}{l}\text { History of coronary } \\
\text { artery disease }\end{array}$ & $119(38)$ & $95(36)$ & $24(47)$ & 0.14 & $61(33)$ & $58(45)$ & $0.03^{*}$ \\
\hline $\begin{array}{l}\text { Hystory of } \\
\text { hypertension }\end{array}$ & $165(53)$ & $114(55)$ & $21(41)$ & 0.075 & $99(54)$ & $65(51)$ & 0.56 \\
\hline Hystory of COPD & $123(39)$ & $105(40)$ & $18(35)$ & 0.53 & $69(38)$ & $54(42)$ & 0.42 \\
\hline History of malignancy & $61(19)$ & $41(16)$ & $20(39)$ & $<0.0001$ & $21(12)$ & $39(31)$ & $<0.0001$ \\
\hline \multicolumn{8}{|c|}{ Etiology of respiratoy failure- $n(\%)$} \\
\hline Heart failure (HF) alone & $101(32)$ & $86(33)$ & $15(30)$ & 0.64 & $67(37)$ & $34(27)$ & 0.06 \\
\hline $\begin{array}{l}\mathrm{HF}+\text { any additional } \\
\text { diagnosis }\end{array}$ & $75(24)$ & $61(23)$ & $14(28)$ & 0.51 & $40(22)$ & $35(27)$ & 0.26 \\
\hline $\mathrm{HF}+$ pneumonia & $42(14)$ & $32(12)$ & $10(20)$ & 0.15 & $16(9)$ & $26(20)$ & 0.003 \\
\hline $\mathrm{HF}+\mathrm{AECOPD}^{f}$ & $20(6)$ & $18(7)$ & $2(4)$ & 0.44 & $17(9)$ & $3(2)$ & 0.014 \\
\hline $\begin{array}{l}\mathrm{HF}+\text { other } \\
\text { diagnosis }\end{array}$ & $13(4)$ & $11(4)$ & $2(4)$ & 0.93 & $7(3)$ & $6(5)$ & 0.71 \\
\hline Pneumonia & $50(16)$ & $38(15)$ & $12(24)$ & 0.11 & $27(15)$ & $22(17)$ & 0.57 \\
\hline AECOPD & $30(10)$ & $26(10)$ & $4(8)$ & 0.66 & $15(8)$ & $15(12)$ & 0.31 \\
\hline Pneumonia + AECOPD & $11(3.5)$ & $10(4)$ & $1(2)$ & 0.52 & $5(3)$ & $6(5)$ & 0.36 \\
\hline Pulmonary embolism & $15(5)$ & $14(5)$ & $1(2)$ & 0.31 & $8(4)$ & $6(5)$ & 0.90 \\
\hline
\end{tabular}


Table 1 Baseline characteristics of study population (Continued)

\begin{tabular}{|c|c|c|c|c|c|c|c|}
\hline Unknown cause & $4(1)$ & $4(1.5)$ & $0(0)$ & 0.38 & $1(1)$ & $2(1)$ & 0.37 \\
\hline Other cause & $28(9)$ & $24(9)$ & $4(8)$ & 0.77 & $20(11)$ & $8(6)$ & 0.16 \\
\hline \multicolumn{8}{|c|}{ Admission medication - $n$ (\%) } \\
\hline Nitrates & $29(11)$ & $27(12)$ & $2(5)$ & 0.19 & $22(15)$ & $7(7)$ & 0.04 \\
\hline ACEi/ARB ${ }^{g}$ & $144(46)$ & $126(48)$ & $18(35)$ & 0.09 & $91(50)$ & $50(39)$ & 0.06 \\
\hline Beta-blocker & $101(32)$ & $94(36)$ & $7(14)$ & 0.001 & $81(44)$ & $20(16)$ & $<0.0001$ \\
\hline Statins & $80(31)$ & $67(30)$ & $13(33)$ & 0.69 & $54(36)$ & $26(24)$ & 0.05 \\
\hline Aspirin/Clopidogrel & $102(39)$ & $86(39)$ & $16(41)$ & 0.80 & $67(44)$ & $35(33)$ & 0.07 \\
\hline Calcium-antagonists & $43(17)$ & $36(16)$ & 7 (18) & 0.79 & $25(17)$ & $18(17)$ & 0.92 \\
\hline Coumarines & $86(33)$ & 77 (35) & $9(23)$ & 0.15 & $46(31)$ & $39(37)$ & 0.31 \\
\hline Beta-mimetics & $94(36)$ & $78(35)$ & $16(41)$ & 0.48 & $49(33)$ & $44(41)$ & 0.15 \\
\hline Oral steroids & $45(17)$ & $38(17)$ & 7 (18) & 0.89 & $28(19)$ & $16(15)$ & 0.45 \\
\hline Diuretics & $130(41)$ & - & - & - & $86(47)$ & $44(34)$ & 0.12 \\
\hline Nitrates & $39(13)$ & - & - & - & $23(13)$ & $16(13)$ & 0.966 \\
\hline ACEi/ARB & $160(51)$ & - & - & - & $121(66)$ & $38(30)$ & 0.010 \\
\hline Beta-blocker & $119(38)$ & - & - & - & $84(46)$ & $34(27)$ & $<0.001$ \\
\hline Statins & $77(25)$ & - & - & - & $56(31)$ & $20(16)$ & 0.001 \\
\hline Aspirin/Clopidogrel & $91(29)$ & - & - & - & $61(33)$ & $29(23)$ & 0.024 \\
\hline Calcium-antagonists & $30(10)$ & - & - & - & $22(12)$ & $8(6)$ & 0.057 \\
\hline Coumarines & $104(33)$ & - & - & - & $67(37)$ & $36(28)$ & 0.075 \\
\hline Beta-mimetics & $89(28)$ & - & - & - & $55(30)$ & $32(25)$ & 0.272 \\
\hline Oral steroids & $41(13)$ & - & - & - & $20(11)$ & $21(16)$ & 0.156 \\
\hline
\end{tabular}

${ }^{\mathrm{a}}$ BMI, body mass index (mass $(\mathrm{kg}) /$ height $\left.(\mathrm{m})^{2}\right){ }^{\mathrm{b}}$ SAPS 2, Simplified Acute Physiology Score [45]; ${ }^{\mathrm{c}}$ measured by echocardiography in 128 patients; ${ }^{\mathrm{d}}$ estimated glomerular filtration rate using Modification of Diet in Renal Disease (MDRD) formula [46]; ${ }^{\text {e } C O P D}$, chronic obstructive pulmonary disease; ${ }^{\mathrm{f}}$ AECOPD, acute exacerbation of COPD; ${ }^{9} \mathrm{ACEi}$, angiotensin-converting enzyme inhibitors. ARB, angiotensin receptor blocker.

Values are displayed as median (interquartile range) or number of patients (\%).

Table 2 Final discharge diagnoses of studied patients

\begin{tabular}{ll}
\hline Characteristic & $(\boldsymbol{n}=\mathbf{3 1 4})$ \\
\hline Heart failure (HF) & $101(32)$ \\
HF + any additional diagnosis & $75(24)$ \\
$\quad$ HF + pneumonia & $42(13)$ \\
$\quad$ HF + obstructive pulmonary disease & $20(6)$ \\
$\quad$ HF + other diagnosis & $13(4)$ \\
Pneumonia & $50(16)$ \\
Obstructive pulmonary disease & $30(10)$ \\
Pneumonia + obstructive pulmonary disease & $11(3)$ \\
Pulmonary embolism & $15(5)$ \\
Unknown cause & $4(1)$ \\
Other cause & $28(9)$
\end{tabular}

ancluding aspiration, anaemia, atelectasis, pneumothorax, oversedation, interstitial lung disease, obesity hypoventilation syndrome and pleural effusion.

fibrillation, creatinine, blood urea nitrogen (BUN) or uric acid levels as well as treatment with oral steroids at discharge were associated with an increased risk of oneyear mortality (Table 3). By contrast, treatment with oral beta-blockers, statins, aspirin and/or clopidogrel at admission, as well as ACEi/ARB at discharge was associated with a lower risk for one-year mortality.
Multivariate analysis shows that history of CAD or history of malignancy was associated with an increased risk and oral beta-blocker treatment prior to admission with a decreased risk of one-year mortality (Table 4).

Univariate analysis shows that a history of malignancy, BMI, atrial fibrillation and creatinine levels on admission were associated with an increased risk of in-hospital mortality. By contrast, treatment with oral beta-blockers prior to admission was associated with a lower risk of in-hospital mortality. Multivariate analysis shows that history of malignancy was associated with an increased risk and oral beta-blocker treatment prior to admission with a decreased risk of in-hospital mortality in ICU patients with acute respiratory failure (Table 4).

\section{Impact of oral beta-blockers on short and long term outcome}

Table 5 displays the different beta-blocker agents and the mean dosage administered during hospitalization. Kaplan-Meier analysis confirmed a lower in-hospital and one-year mortality in ARF patients admitted with than without oral beta-blockers $(P=0.001$ for in-hospital and $P<0.001$ for one-year mortality respectively) (Figure 1). The beneficial effect of oral 
Table 3 Predictors of one-year mortality by univariate analysis $(n=314)$

\begin{tabular}{lll}
\hline & HR (95\%Cl) & $P$-value \\
\hline Age & $1,03(1.01$ to 1.06$)$ & 0.0012 \\
Diastolic blood pressure & $0.98(0.97$ to 0.99$)$ & 0.0025 \\
Body mass index & $0.96(0.92$ to 0.98$)$ & 0.031 \\
History of malignancy & $1.99(1.18$ to 3.32$)$ & 0.0093 \\
Atrial fibrillation & $1.86(1.06$ to 3.33$)$ & 0.033 \\
Creatinin levels at admission & $1.00(1$ to 1.01$)$ & 0.048 \\
Blood urea nitrogen levels at admission & $1.01(1$ to 1.02$)$ & 0.02 \\
Uric acid levels at admission & $1.00(1$ to 1$)$ & 0.048 \\
Beta-blockers at admission & $0.32(0.18$ to 0.52$)$ & $<0.0001$ \\
Statins at admission & $0.51(0.28$ to 0.94$)$ & 0.03 \\
Aspirin/Clopidogrel at admission & $0.56(0.33$ to 0.95$)$ & 0.03 \\
ACEi/ARB at discharge & $0.56(0.36$ to 0.88$)$ & 0.011 \\
Oral steroids at discharge & $2.34(1.37$ to 4.01$)$ & 0.0019 \\
\hline ACEl angoteninconveting
\end{tabular}

ACEi, angiotensin-converting enzyme inhibitors; ARB, angiotensin receptor blocker; $\mathrm{Cl}$, confidence interval; $\mathrm{HR}$, hazard ratio.

beta-blockers at admission on one-year mortality holds true in the two subgroups of ARF related to cardiac or non-cardiac causes (Figure 1).

We further explored whether oral beta-blockers at discharge would give an additional beneficial effect on long term outcome. Kaplan-Meier analysis shows that administration of oral beta-blockers before hospital discharge gives striking additional beneficial effects on one-year mortality in our ARF patients. A beneficial effect of oral beta-blockers at discharge is seen regardless of the cardiac or non-cardiac origin of ARF (Figures 2 and 3 ).

\section{Discussion}

The present study focuses on the predictors of inhospital and one-year mortality in ICU patients with acute respiratory failure. Our study confirms the negative impact of renal dysfunction on in-hospital survival and of malignancy and history of CAD on one-year survival. Further, a positive impact on one-year overall survival was seen in patients given beta-blockers prior to admission. Discontinuation of beta-blocker therapy in patients admitted on beta-blockers was associated with higher mortality.
Short and long-term mortality has been studied in some surveys and trials involving ICU patients with a primary diagnosis of ADHF, AECOPD or acute pneumonia [6-9,11-13,16]. However, data describing mortality in ICU patients admitted for acute respiratory failure indifferent to underlying etiology are rare. In the present study, inhospital mortality was $16 \%$ and 30 -day mortality $20 \%$. This suggests that most of the initial deaths occurred during the initial hospitalization with only a few deaths occurring shortly after discharge. One-year mortality in our ICU patients was $41 \%$, in line with mortality rates previously described in selected ICU patients hospitalized for ADHF [6], AECOPD [11,17] or severe pneumonia (14).

Our study shows for the first time that ICU patients with acute respiratory failure treated by oral beta-blockers prior to hospital admission experienced lower inhospital and one-year mortality. The positive impact of being treated with oral beta-blockers at the time of respiratory failure in ICU patients was unknown. Exact mechanisms of a better short term and long-term survival in patients being treated with oral beta-blockers at the time of respiratory failure remained to be explored. One assumable explication may be the relevant co-morbidities found in our patients including history of CAD in $38 \%$, history of $\mathrm{CHF}$ in $27 \%$, arterial hypertension in $53 \%$ and COPD in $39 \%$ and the positive effect of betablocker therapy in these different diseases. This may include an adequate control of the sympathetic nervous system in patients with CAD, CHF or arterial hypertension as well as a possible improvement of bronchodilator responsiveness and effectiveness of inhaled $\beta_{2}$-sympathicomimetics in patients with AECOPD.

More importantly, we could demonstrate that discontinuation of beta-blocker therapy during hospitalization is associated with higher mortality rates, suggesting a protective effect of beta-blocker therapy in our acute respiratory failure patients. Discontinuation of betablocker therapy is indeed associated with a "withdrawal syndrome", a transient sympathetic hyper-response caused by hypersensitivity of cardiac $\beta$-receptors [18]. Patients in whom beta-blockers were discontinued complained of transient palpitations, tremor, sweating, headache and general malaise. A significant increase in blood pressure and heart rate could also be demonstrated $24 \mathrm{~h}$ after beta-blocker withdrawal [19]. A survival benefit of

Table 4 Independent predictors of in-hospital and one-year mortality by multivariate analysis

\begin{tabular}{|c|c|c|c|c|}
\hline & In-hospital mortality $(n=51)$ & & One-year overall mortality $(n=128)$ & \\
\hline & HR $(95 \% \mathrm{Cl})$ & $P$-value & $\mathrm{HR}(95 \% \mathrm{Cl})$ & $P$-value \\
\hline Beta-blockers at admission & 0.33 (0.14 to 0.74$)$ & 0.007 & 0.29 (0.16 to 0.51$)$ & 0.0003 \\
\hline History of malignancy & $2.7(1.5$ to 4.9$)$ & 0.0012 & $2.75(1.70$ to 4.43$)$ & 0.0003 \\
\hline History of coronary artery disease & - & - & $1.81(1.15$ to 2.82$)$ & 0.009 \\
\hline
\end{tabular}

$\mathrm{Cl}$, indicates confidence interval; $\mathrm{HR}$, hazard ratio. 
Table 5 Different agents and mean dosages of beta-blocker administered at presentation, at 24 hours and at discharge

\begin{tabular}{lllllll}
\hline $\begin{array}{l}\text { Beta- } \\
\text { blocker }\end{array}$ & $\begin{array}{l}\text { Hospital admission } \\
\mathbf{n}(\%)\end{array}$ & $\begin{array}{l}\text { mean dosage } \\
\text { (mg) }\end{array}$ & $\begin{array}{l}\text { 24-hour } \\
\mathbf{n}(\%)\end{array}$ & $\begin{array}{l}\text { mean dosage } \\
\text { (mg) }\end{array}$ & $\begin{array}{l}\text { Hospital discharge } \\
\mathbf{n}(\%)\end{array}$ & $\begin{array}{l}\text { mean dosage } \\
\text { (mg) }\end{array}$ \\
\hline Metoprolol & $36(36)$ & $100(50$ to 125$)$ & $30(36)$ & $100(50$ to 125 & $51(43)$ & $100(50$ to 125 \\
Carvedilol & $18(18)$ & $12.5(6.25$ to 25$)$ & $16(19)$ & $12.5(6.25$ to 25$)$ & $20(17)$ & $12.5(7.81$ to 25) \\
Bisoprolol & $16(16)$ & $5(5$ to 8.75$)$ & $13(16)$ & $5(5$ to 5$)$ & $19(16)$ & $5(5$ to 5$)$ \\
Nebivolol & $22(22)$ & $5(3.75$ to 7.5$)$ & $19(24)$ & $5(2.5$ to 7.5$)$ & $26(22)$ & $5(2.5$ to 7.5$)$ \\
Atenolol & $4(4)$ & $62(50$ to 94$)$ & $2(2.5)$ & $75(50$ to 100$)$ & $1(1)$ & 100 \\
Sotalol & $3(3)$ & 160 & 0 & - & 0 & - \\
Celiproplol & $2(2)$ & 200 & $2(2.5)$ & $150(100$ to 200) & $1(1)$ & 200 \\
\hline
\end{tabular}

Values are displayed as number of patients (\%) and mean (quartiles) dosage in $\mathrm{mg}$.

continuation of beta-blocker therapy in patients with ADHF was demonstrated by Butler et al. [20] and recently confirmed by Fonarow et al. [21], Jondeau et al. [22] and Orso et al. [23]. There is, furthermore, evidence that patients admitted with AECOPD may also benefit from continuation of beta-blocker therapy [24].
The observed positive association of beta-blocker continuation with lower mortality may be explained by the prevention of malignant ventricular arrhythmias, protection against myocardial infarction or acute negative mechanical remodeling, which may initiate the development of fatal pump failure [23,25].
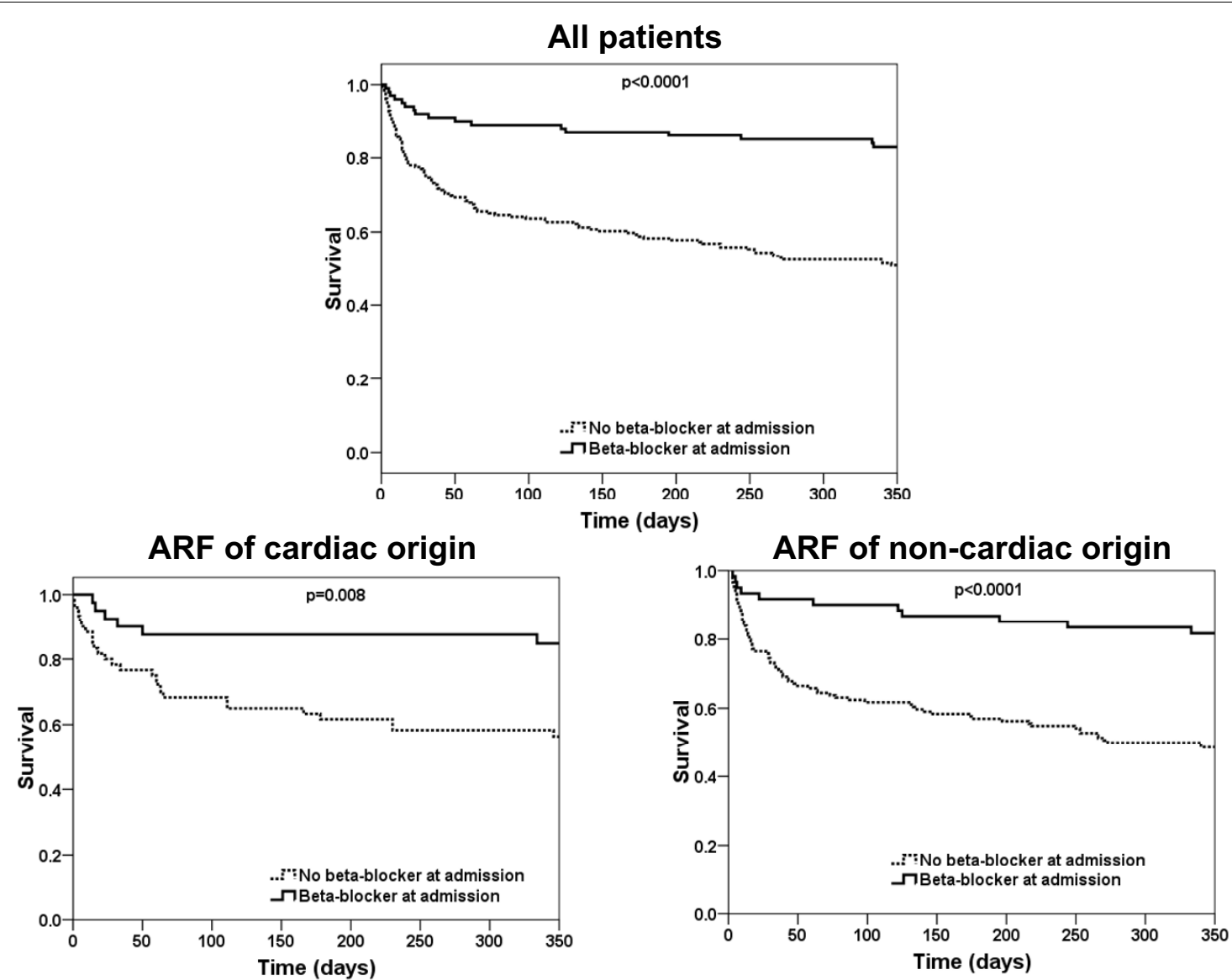

Figure 1 Impact of beta-blocker at admission on long-term outcome. Upper panel: Kaplan-Meier curve displaying overall one-year mortality in ICU patients with acute respiratory failure with or without treatment with beta-blocker at admission $(P<0.001$ by Log Rank). Lower panel: Kaplan-Meier curve displaying one-year mortality with or without treatment with beta-blocker at admission in patients with cardiac aetiology of respiratory failure (adjudicated final diagnosis of heart failure; $P=0.008$ ) and patients with non-cardiac aetiology of respiratory failure (adjudicated final diagnosis other than heart failure; $P<0.0001$ ). 


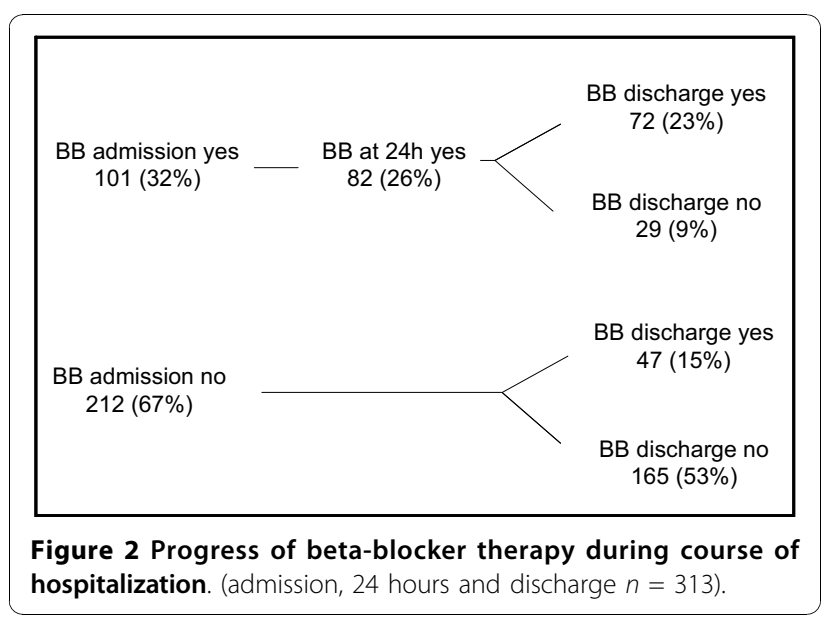

In our study, treatment with beta-blockers at discharge was associated with lower one-year mortality. There is solid evidence showing that oral treatment with beta-blockers improves long-term survival in various cardiovascular diseases including CHF, CAD or arterial hypertension [26-29]. A recently published, large observational cohort study demonstrated that treatment with beta-blockers also reduce risk of exacerbations and improve survival in patients with COPD [30]. Interestingly, this effect was shown to be independent of cardiovascular co-morbidities. Beta-blockers are known to temper the sympathetic nervous system, including the reduction of heart rate. Therefore, negative systemic effects in the disease progression of cardiovascular disease including $\mathrm{CAD}, \mathrm{CHF}$ or arterial hypertension, as well as COPD [31] could be diminished. Heart rate reduction itself may be an important mechanism of the benefit of beta-blockers. Large epidemiological studies have shown that resting heart rate was an independent predictor of all-cause mortality in individuals with and without cardiovascular disease [24].

Angiotensin converting enzyme inhibitors (ACEi)/ angiotensin receptor blockers (ARB) and beta-blockers build the mainstay of therapy in patients with CHF and/ or CAD with impaired left ventricular function [32]. In our study, treatment with ACEi/ARB was also associated with improved one-year survival. Importantly, lower inhospital and one-year mortality benefits of beta-blocker therapy demonstrated in our study was independent of concomitant ACEi/ARB treatment.

Interestingly, the present study shows that the beneficial effect of beta-blockers on survival was consistently

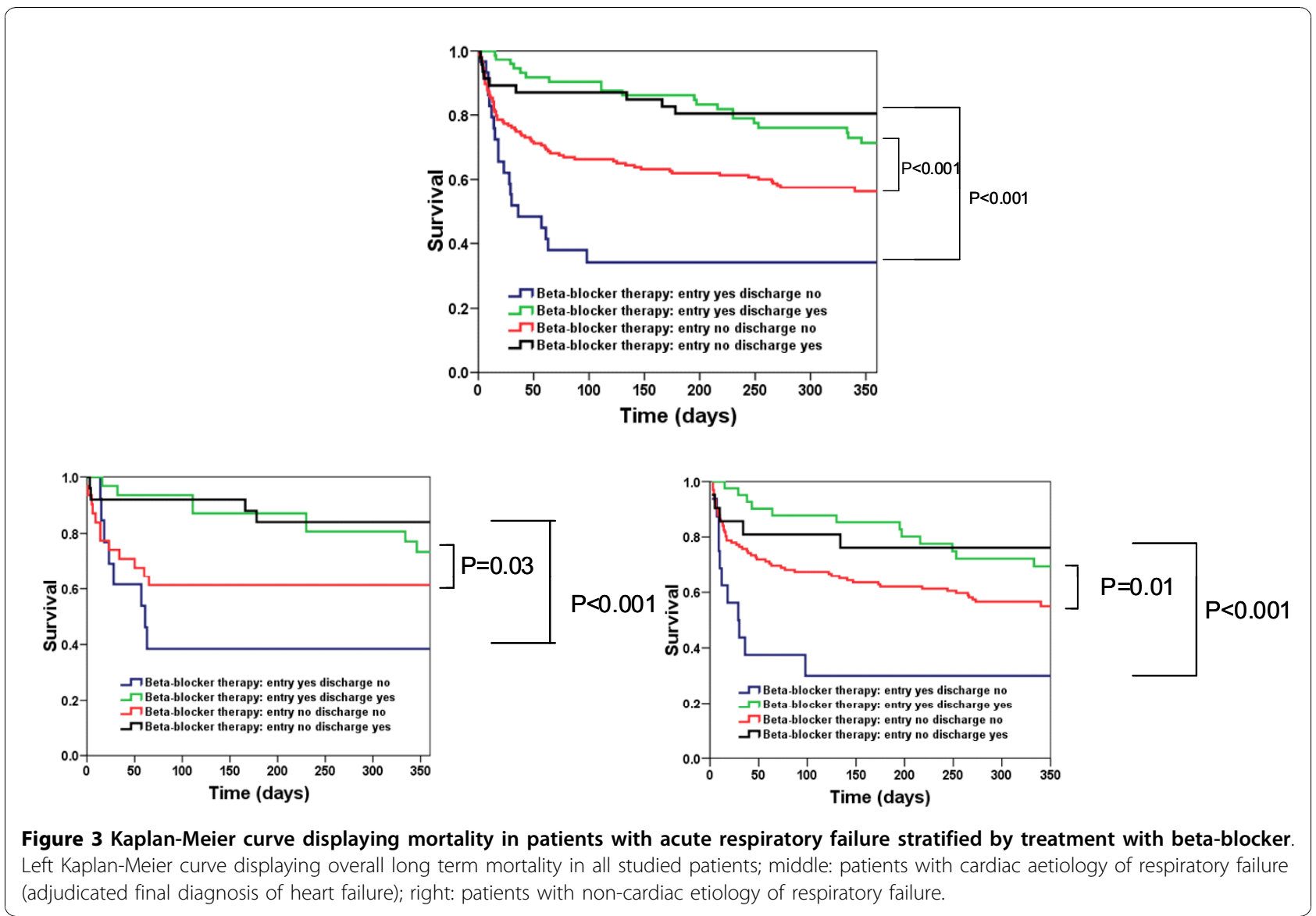


present regardless of a cardiac or non-cardiac etiology of respiratory failure. The beneficial effect of beta-blockers in the non-cardiac respiratory failure group might seem to be a paradox. However, again the high incidence of relevant cardiovascular co-morbidities known to benefit from beta-blocker treatment may explain this finding. Beta-blocker treatment has been shown to reduce mortality in patients with COPD and arterial hypertension compared with other antihypertensive agents and to reduce cardiac toxicity of short-acting beta-agonists $[33,34]$.

Our study corroborates and extends this finding to ICU patients with respiratory failure. While early diagnosis is often difficult to perform in ICU patients presenting with acute respiratory failure, this finding may be of major clinical importance. Roughly one-third of our patients were treated with beta-blockers at admission suggesting frequent uncertainty in ICU physicians regarding the question of whether beta-blocker therapy should be continued or not. Our data advocate for a continuation of beta-blocker therapy in this patient group, although study design and power were not conceived for analysis of this issue.

In our study elevated uric acid levels were associated with increased one-year mortality in univariate analysis. In patients admitted with acute dyspnea at the emergency department, uric acid levels were demonstrated to be higher in dyspnea due to ADHF compared to other etiologies [35]. In this study uric acid levels also independently predicted two-year all-cause mortality. Our study expands these findings to ICU patients with acute respiratory failure. Uric acid is known to be associated with most cardiovascular risk factors and components of the metabolic syndrome including arterial hypertension, hyperlipidemia, or diabetes mellitus [36-38]. Uric acid levels reflect the degree of circulating xanthine oxidase activity which is stimulated by various cardiovascular diseases and is an important source of free radicals $[39,40]$. Accordingly, levels of uric acid might reflect a composite of cardiovascular risk factors.

Another important predictor of one-year mortality in our study was a low BMI. Previous studies demonstrated that a low BMI is associated with adverse outcome. This finding was recently confirmed in a large ICU database including 41,011 patients [41]. In this study low BMI also prolonged ICU and hospital length of stay. These findings were regardless of severity of illness quantified by SAPS II score.

A more intriguing finding of our study was the association of a low diastolic blood pressure with increased one-year mortality, even when only found in univariate analysis. At the same time, beta-blocker treatment which lowers diastolic blood pressure improved outcome. Low diastolic blood pressure is known to affect microcirculation particularly in the coronary bed, and was previously demonstrated to be associated with higher mortality in older patients [42]. Patients with severe forms of hypertension and overt coronary ischemia especially show a J-shaped relation between diastolic blood pressure during treatment and myocardial infarction [43]. The J-curve seems to be independent of treatment, pulse pressure, and the degree of decrease in diastolic blood pressure, and is unlikely to be caused by poor left ventricular function. The most probable explanation is that subjects who have severe coronary artery disease and concomitant arterial hypertension may have a poor coronary flow reserve, which makes the myocardium vulnerable to coronary perfusion pressures that are tolerated by patients without ischemia, particularly at high heart rates [44]. The most suitable explanation for this conflicting finding in our study is that patients with acute coronary syndrome as well as patients with shock were excluded due to study protocol. Patients included in our study had diastolic blood pressures that were still in a normal range (mean 62; 95\% CI (53 to 74.5) $\mathrm{mmHg}$ ).

\section{Study limitations}

There are limitations to our study design and conclusions, related to the post hoc nature of the analyses. Patients were not randomized into the study according to the beta-blocker status at baseline. However, patients currently being treated with oral beta-blockers at the time of acute respiratory failure had consistently lower in-hospital and one-year overall mortality. Accordingly, the impact of beta-blocker therapy on inhospital and one-year survival merits further confirmation by an appropriate trial. Also, data regarding duration of beta-blocker therapy prior to admission, as well as percentage of beta-blocker therapy at one-year follow-up cannot be provided. Due to the exclusion of patients with sepsis or shock our findings cannot be generalized to these subgroups of ICU patients. No adjustment for APACHE or SAPS II score has been performed in our linear regression model. The most relevant variables of both severity scores have, however, been considered.

\section{Conclusions}

In our analysis established beta-blocker therapy appears to be associated with reduced mortality in patients admitted to the intensive care unit with acute respiratory failure. Cessation of established therapy appears to be hazardous. Initiation of therapy prior to discharge appears to confer benefit. This finding was seen regardless of the cardiac or non-cardiac etiology of respiratory failure. This observation should be confirmed by a large study that is adequately powered. 


\section{Key messages}

- Beta-blocker therapy at admission appears to be associated with a reduced mortality in patients admitted to the intensive care unit with acute respiratory failure.

- Cessation of established beta-blocker therapy in ICU patients admitted with acute respiratory failure appears to be hazardous.

- Initiation of beta-blocker therapy prior to hospital discharge appears to confer benefits. This finding was seen regardless of the cardiac or non-cardiac etiology of respiratory failure.

\section{Abbreviations}

ACEl: angiotensin converting enzyme inhibitor; ADHF: acute decompensated heart failure; AECOPD: acute exacerbation of chronic obstructive pulmonary disease; ARB: angiotensin receptor blocker; ARF: acute respiratory failure; ASS: aspirin; BASEL: Acute Shortness of Breath Evaluation; BMl: body mass index; BNP: B-type natriuretic peptide; BUN: blood urea nitrogen; CAD: coronary artery disease; CAP: community acquired pneumonia; CHF: congestive heart failure; PE: pulmonary embolism; PTT: partial thromboplastin time; WBC: white blood count.

\section{Acknowledgements}

We are indebted to the ICU staff at the participating hospitals for their most valuable efforts, all participating patients, their relatives, as well as Stephan Marsch MD, Patrick Hunziker, MD, Martin Sigemund, MD, Anja Balthusen MD, Ronald Schoenenberger, MD, Serge Elsasser, MD, Patricia Manndorff, MD, Michael Christ, MD, Lukas Fischler, MD, Mario Portner, MD, Franziska Kunz, MD, Christian Arranto, MD, Christoph Haberthür, MD, Kirsten Hochholzer, MSc, Petr Maly, MD, Sevgi Cayir, MD, and Martina Viglino, MD, for their help in patient recruitment and data management.

This study was supported by research grants from the Swiss National Science Foundation (PP00B-102853), the Novartis Foundation, the Krokus Foundation, Abbott, Biosite, and the Department of Internal Medicine, University Hospital Basel.

The sponsors had no role in study design, data analysis and interpretation.

\section{Author details}

${ }^{1}$ Department of Internal Medicine, University Hospital Basel, Petersgraben 4, 4053 Basel, Switzerland. ²Department of Cardiology, University Hospital Basel, Petersgraben 4, 4053 Basel, Switzerland. ${ }^{3}$ Department of Anesthesiology and Critical Care Medicine, Université Paris Diderot and Hospital Lariboisière, 2, rue Ambroise - Paré, 75475 PARIS Cedex 10, France. ${ }^{4}$ Operative Intensive Care, University Hospital Basel, Petersgraben 4, 4053 Basel, Switzerland. ${ }^{5}$ Intensive Care Unit, Spital Thun-Simmental AG, Krankenhausstrasse 12, 3600 Thun, Switzerland.

\section{Authors' contributions}

MN made substantial contributions to conception and design, acquisition of data, analysis and interpretation of data, and the manuscript draft. TB, TR, $M P, H P, A H, J M, R T, N M$ and $A M$ contributed to acquisition of data and critical revision of the manuscript. AM, also, contributed to analysis and interpretation of the data and to the manuscript draft. EG contributed to analysis and interpretation of the data, critical revision of the manuscript, and important statistical support. CM contributed to conception and design, analysis and interpretation of data, manuscript draft, and critical revision of the manuscript.

\section{Competing interests}

Dr. Mueller reported receiving research support from the Swiss National Science Foundation (PP00B-102853), the Swiss Heart Foundation, the Novartis Foundation, the Krokus Foundation, Abbott, Astra Zeneca, Biosite, Brahms, Roche, Siemens, and the Department of Internal Medicine, University Hospital Basel, as well as speaker honoraria from Abbott, Biosite,
Brahms, Roche, and Siemens. The other authors reported no financial disclosures.

Received: 9 May 2010 Revised: 14 July 2010

Accepted: 3 November 2010 Published: 3 November 2010

\section{References}

1. Ware LB, Matthay MA: The acute respiratory distress syndrome. N Engl J Med 2000, 342:1334-1349.

2. Ware LB, Matthay MA: Clinical practice. Acute pulmonary edema. $N$ Engl J Med 2005, 353:2788-2796.

3. Vincent JL, Akca S, De Mendonca A, Haji-Michael P, Sprung C, Moreno R, Antonelli $M$, Suter PM: The epidemiology of acute respiratory failure in critically ill patients $(*)$. Chest 2002, 121:1602-1609.

4. Luhr OR, Antonsen K, Karlsson M, Aardal S, Thorsteinsson A, Frostell CG, Bonde J: Incidence and mortality after acute respiratory failure and acute respiratory distress syndrome in Sweden, Denmark, and Iceland. The ARF Study Group. Am J Respir Crit Care Med 1999, 159:1849-1861.

5. Ray $P$, Birolleau $S$, Lefort $Y$, Becquemin $M H$, Beigelman $C$, Isnard $R$, Teixeira A, Arthaud M, Riou B, Boddaert J: Acute respiratory failure in the elderly: etiology, emergency diagnosis and prognosis. Crit Care 2006, 10: R82.

6. Zannad F, Mebazaa A, Juilliere Y, Cohen-Solal A, Guize L, Alla F, Rouge P, Blin P, Barlet MH, Paolozzi L, Vincent C, Desnos M, Samii K: Clinical profile, contemporary management and one-year mortality in patients with severe acute heart failure syndromes: The EFICA study. Eur J Heart Fail 2006, 8:697-705

7. Nieminen MS, Brutsaert D, Dickstein $K$, Drexler H, Follath F, Harjola VP Hochadel M, Komajda M, Lassus J, Lopez-Sendon JL, Ponikowski P, Tavazzi L: EuroHeart Failure Survey II (EHFS II): a survey on hospitalized acute heart failure patients: description of population. Eur Heart J 2006, 27:2725-2736.

8. Rudiger A, Harjola VP, Muller A, Mattila E, Saila P, Nieminen M, Follath F: Acute heart failure: clinical presentation, one-year mortality and prognostic factors. Eur J Heart Fail 2005, 7:662-670.

9. Afessa B, Morales IJ, Scanlon PD, Peters SG: Prognostic factors, clinical course, and hospital outcome of patients with chronic obstructive pulmonary disease admitted to an intensive care unit for acute respiratory failure. Crit Care Med 2002, 30:1610-1615.

10. Connors AF Jr, Dawson NV, Thomas C, Harrell FE Jr, Desbiens N, Fulkerson WJ, Kussin P, Bellamy P, Goldman L, Knaus WA: Outcomes following acute exacerbation of severe chronic obstructive lung disease. The SUPPORT investigators (Study to Understand Prognoses and Preferences for Outcomes and Risks of Treatments). Am J Respir Crit Care Med 1996, 154:959-967.

11. Seneff MG, Wagner DP, Wagner RP, Zimmerman JE, Knaus WA: Hospital and 1-year survival of patients admitted to intensive care units with acute exacerbation of chronic obstructive pulmonary disease. JAMA 1995, 274:1852-1857.

12. Torres A, Serra-Batlles J, Ferrer A, Jimenez P, Celis R, Cobo E, RodriguezRoisin R: Severe community-acquired pneumonia. Epidemiology and prognostic factors. Am Rev Respir Dis 1991, 144:312-318.

13. Leroy O, Vandenbussche C, Coffinier C, Bosquet C, Georges H, Guery B, Thevenin D, Beaucaire G: Community-acquired aspiration pneumonia in intensive care units. Epidemiological and prognosis data. Am J Respir Crit Care Med 1997, 156:1922-1929.

14. Fine MJ, Smith MA, Carson CA, Mutha SS, Sankey SS, Weissfeld LA, Kapoor WN: Prognosis and outcomes of patients with communityacquired pneumonia. A meta-analysis. JAMA 1996, 275:134-141.

15. Noveanu $M$, Parger $H$, Breidthardt $T$, Reichlin $T$, Schindler $C$, Heise $A$, Schoenenberger R, Manndorff $P$, Siegemund M, Mebazaa A, Marsch S, Mueller C: Use of B-type natriuretic peptide in the management of hypoxemic respiratory failure. Eur J Heart Fail 2010.

16. Woodhead MA, Macfarlane JT, Rodgers FG, Laverick A, Pilkington R, Macrae AD: Aetiology and outcome of severe community-acquired pneumonia. J Infect 1985, 10:204-210.

17. Ai-Ping C, Lee KH, Lim TK: In-hospital and 5-year mortality of patients treated in the ICU for acute exacerbation of COPD: a retrospective study. Chest 2005, 128:518-524. 
18. Lewis MJ, Ross PJ, Henderson AH: Rebound effect after stopping betablockers. Br Med J 1979, 2:606.

19. Lederballe Pedersen O, Mikkelsen E, Lanng Nielsen J, Christensen NJ: Abrupt withdrawal of beta-blocking agents in patients with arterial hypertension. Effect on blood pressure, heart rate and plasma catecholamines and prolactin. Eur J Clin Pharmacol 1979, 15:215-217.

20. Butler J, Young JB, Abraham WT, Bourge RC, Adams KF Jr, Clare R, O'Connor C: Beta-blocker use and outcomes among hospitalized heart failure patients. J Am Coll Cardiol 2006, 47:2462-2469.

21. Fonarow GC, Abraham WT, Albert NM, Stough WG, Gheorghiade M, Greenberg BH, O'Connor CM, Sun JL, Yancy CW, Young JB: Influence of beta-blocker continuation or withdrawal on outcomes in patients hospitalized with heart failure: findings from the OPTIMIZE-HF program. J Am Coll Cardiol 2008, 52:190-199.

22. Jondeau $G$, Neuder $Y$, Eicher JC, Jourdain P, Fauveau E, Galinier M, Jegou A, Bauer F, Trochu JN, Bouzamondo A, Tanguy ML, Lechat P: B-CONVINCED: Beta-blocker CONtinuation Vs. INterruption in patients with Congestive heart failure hospitalizED for a decompensation episode. Eur Heart J 2009, 30:2186-2192.

23. Orso F, Baldasseroni S, Fabbri G, Gonzini L, Lucci D, D’Ambrosi C, Gobbi M, Lecchi G, Randazzo S, Masotti G, Tavazzi L, Maggioni AP: Role of betablockers in patients admitted for worsening heart failure in a real world setting: data from the Italian Survey on Acute Heart Failure. Eur J Heart Fail 2009, 11:77-84

24. Dransfield MT, Rowe SM, Johnson JE, Bailey WC, Gerald LB: Use of beta blockers and the risk of death in hospitalised patients with acute exacerbations of COPD. Thorax 2008, 63:301-305.

25. Psaty BM, Koepsell TD, Wagner EH, LoGerfo JP, Inui TS: The relative risk of incident coronary heart disease associated with recently stopping the use of beta-blockers. JAMA 1990, 263:1653-1657.

26. Effect of metoprolol $\mathrm{CR} / \mathrm{XL}$ in chronic heart failure: Metoprolol $\mathrm{CR} / \mathrm{XL}$ Randomised Intervention Trial in Congestive Heart Failure (MERIT-HF). Lancet 1999, 353:2001-2007.

27. The Cardiac Insufficiency Bisoprolol Study II (CIBIS-II): a randomised trial. Lancet 1999, 353:9-13.

28. Leizorovicz A, Lechat P, Cucherat M, Bugnard F: Bisoprolol for the treatment of chronic heart failure: a meta-analysis on individual data of two placebo-controlled studies-CIBIS and CIBIS II. Cardiac Insufficiency Bisoprolol Study. Am Heart J 2002, 143:301-307.

29. Packer M, Fowler MB, Roecker EB, Coats AJ, Katus HA, Krum H, Mohacsi P, Rouleau JL, Tendera M, Staiger C, Holcslaw TL, Amann-Zalan I, DeMets DL: Effect of carvedilol on the morbidity of patients with severe chronic heart failure: results of the carvedilol prospective randomized cumulative survival (COPERNICUS) study. Circulation 2002, 106:2194-2199.

30. Rutten FH, Zuithoff NP, Hak E, Grobbee DE, Hoes AW: Beta-blockers may reduce mortality and risk of exacerbations in patients with chronic obstructive pulmonary disease. Arch Intern Med 170:880-887.

31. Andreas S, Anker SD, Scanlon PD, Somers VK: Neurohumoral activation as a link to systemic manifestations of chronic lung disease. Chest 2005, 128:3618-3624.

32. Dickstein K, Cohen-Solal A, Filippatos G, McMurray JJ, Ponikowski P, PooleWilson PA, Stromberg A, van Veldhuisen DJ, Atar D, Hoes AW, Keren A, Mebazaa A, Nieminen M, Priori SG, Swedberg K, Vahanian A, Camm J, De Caterina R, Dean V, Funck-Brentano C, Hellemans I, Kristensen SD, McGregor K, Sechtem U, Silber S, Tendera M, Widimsky P, Zamorano JL: ESC Guidelines for the diagnosis and treatment of acute and chronic heart failure 2008: the Task Force for the Diagnosis and Treatment of Acute and Chronic Heart Failure 2008 of the European Society of Cardiology. Developed in collaboration with the Heart Failure Association of the ESC (HFA) and endorsed by the European Society of Intensive Care Medicine (ESICM). Eur Heart J 2008, 29:2388-2442.

33. Au DH, Curtis JR, Every NR, McDonell MB, Finn SD: Association between inhaled beta-agonists and the risk of unstable angina and myocardial infarction. Chest 2002, 121:846-851.

34. Au DH, Bryson CL, Fan VS, Udris EM, Curtis JR, McDonell MB, Fihn SD: Betablockers as single-agent therapy for hypertension and the risk of mortality among patients with chronic obstructive pulmonary disease. Am J Med 2004, 117:925-931.

35. Reichlin T, Potocki M, Breidthardt $T$, Noveanu M, Hartwiger S, Burri E, Klima T, Stelzig C, Laule K, Mebazaa A, Christ M, Mueller C: Diagnostic and prognostic value of uric acid in patients with acute dyspnea. Am J Med 2009, 122:1054.e7-1054.e14.

36. Johnson RJ, Kang DH, Feig D, Kivlighn S, Kanellis J, Watanabe S, Tuttle KR, Rodriguez-Iturbe B, Herrera-Acosta J, Mazzali M: Is there a pathogenetic role for uric acid in hypertension and cardiovascular and renal disease? Hypertension 2003, 41:1183-1190.

37. Cannon PJ, Stason WB, Demartini FE, Sommers SC, Laragh JH Hyperuricemia in primary and renal hypertension. N Engl J Med 1966, 275:457-464.

38. Zavaroni I, Mazza S, Fantuzzi M, Dall'Aglio E, Bonora E, Delsignore R, Passeri M, Reaven GM: Changes in insulin and lipid metabolism in males with asymptomatic hyperuricaemia. J Intern Med 1993, 234:25-30.

39. Leyva F, Anker S, Swan JW, Godsland IF, Wingrove CS, Chua TP, Stevenson JC, Coats AJ: Serum uric acid as an index of impaired oxidative metabolism in chronic heart failure. Eur Heart J 1997, 18:858-865.

40. Terada LS, Guidot DM, Leff JA, Willingham IR, Hanley ME, Piermattei D, Repine JE: Hypoxia injures endothelial cells by increasing endogenous xanthine oxidase activity. Proc Natl Acad Sci USA 1992, 89:3362-3366.

41. Tremblay A, Bandi V: Impact of body mass index on outcomes following critical care. Chest 2003, 123:1202-1207.

42. Protogerou AD, Safar ME, laria P, Safar H, Le Dudal K, Filipovsky J, Henry O, Ducimetiere $\mathrm{P}$, Blacher J: Diastolic blood pressure and mortality in the elderly with cardiovascular disease. Hypertension 2007, 50:172-180.

43. Waller PC, Isles CG, Lever AF, Murray GD, McInnes GT: Does therapeutic reduction of diastolic blood pressure cause death from coronary heart disease? J Hum Hypertens 1988, 2:7-10.

44. Fletcher AE, Beevers DG, Bulpitt CJ, Butler A, Coles EC, Hunt D, MunroFaure AD, Newson R, O'Riordan PW, Petrie JC, et al: The relationship between a low treated blood pressure and IHD mortality: a report from the DHSS Hypertension Care Computing Project (DHCCP). J Hum Hypertens 1988, 2:11-15.

45. Le Gall JR, Lemeshow S, Saulnier F: A new Simplified Acute Physiology Score (SAPS II) based on a European/North American multicenter study. JAMA 1993, 270:2957-2963.

46. Levey AS, Bosch JP, Lewis JB, Greene T, Rogers N, Roth D: A more accurate method to estimate glomerular filtration rate from serum creatinine: a new prediction equation. Modification of Diet in Renal Disease Study Group. Ann Intern Med 1999, 130:461-470.

doi:10.1186/cc9317

Cite this article as: Noveanu et al:: Effect of oral beta-blocker on short and long-term mortality in patients with acute respiratory failure: results from the BASEL II-ICU study. Critical Care 2010 14:R198.

\section{Submit your next manuscript to BioMed Central and take full advantage of:}

- Convenient online submission

- Thorough peer review

- No space constraints or color figure charges

- Immediate publication on acceptance

- Inclusion in PubMed, CAS, Scopus and Google Scholar

- Research which is freely available for redistribution

Submit your manuscript at www.biomedcentral.com/submit
C Biomed Central 